\title{
Como estruturar e escrever um artigo em administração
}

\section{How to structure and write an article in management}

\author{
Manuel Portugal Ferreira ${ }^{1}$
}

\section{Resumo}

Os pesquisadores, talvez mais especialmente os estudantes de Mestrado e Doutorado em Administração e os recém-doutores, são pressionados para pesquisar e publicar em periódicos com impacto. As pesquisas internacionais mostram evidências de que as taxas de rejeição são muito elevadas e é possível que as dificuldades de comunicar sejam superiores às falhas teóricas ou de não seguir os procedimentos metodológicos adequados. Com este ensaio, contribuo para a melhoria dos artigos, apresentando a estrutura do artigo acadêmico e um roteiro de trabalho na redação deste gênero textual. Contar uma história com qualidade na escrita é um componente crucial frequentemente descurado, mas há especificidades em todas as partes do artigo e uma estrutura básica a seguir de modo a atender às expectativas de revisores e leitores. Entender estes roteiros e desenvolver uma prática de pesquisa contribui para a capacidade de os pesquisadores converterem as suas pesquisas em artigos publicáveis.

Palavras-chave: Redação Científica. Publicar em Administração. Organizar o Artigo. Escrita Clara.

\section{Abstract}

Researchers and perhaps more notably masters and doctoral students and the recently graduated Ph.Ds are pressed to research and publish. There is ample international evidence on the high rejection rates of manuscripts submitted to journals and it is possible that the difficulties of communicating are higher than those pertaining to theory or following appropriate methodological procedures and techniques. With this essay we contribute to improve the articles presenting the basic structure that must be followed in organizing the article and a roadmap for working on the writing

Doutor em Administração pela Universidade de Utah. Professor de Estratégia no PPGA da Universidade Nove de Julho - UNINOVE, São Paulo, Brasil.manuel.portugal.ferreira@gmail. com 
of the article. The quality of the writing and telling a story are two crucial components often overlooked but there are specificities to each part of the article and a structure to follow to attend to the expectations of reviewers and readers. Understanding these roadmaps and developing the practice for doing research contributes to researchers' ability to convert their studies into publishable articles.

Keywords: Scientific writing. Publishing in Management.OrganizingtheArticle. ClearWriting

\section{Introdução}

A maioria dos pesquisadores tem dificuldade em verter suas pesquisas em artigo escrito. Escrever para publicar não é fácil. É um trabalho moroso, que exige grande domínio do conhecimento e capacidade de revelá-lo como texto, ao ser redigido de forma clara e simples, de modo que mesmo um leitor não especialista consiga entendê-lo. Escrever exige do pesquisador a capacidade de analisar o que escreveu e observar se é pertinente, ajustado, se está dentro do foco, se é coerente com a história e, sempre que não for adequado, deverá apagá-lo ou reescrevê-lo. Assim, escrever um artigo acadêmico tem mais de reescrita e revisão do que apenas escrita inicial (JONSSON, 2006); ou seja, tem mais de trabalho na revisão do que na inspiração. Seguindo Pollock e Bono (2013), ao afirmarem que os acadêmicos têm dois trabalhos: responder perguntas interessantes e contar a história, neste artigo, analisamos alguns aspectos que ajudam a contar a história por meio de palavras escritas em um artigo acadêmico. Se os pesquisadores almejam suas pesquisas publicadas, necessitam prestar tanta atenção à "arte" da escrita como à "ciência" em si, à questão de pesquisa e aos procedimentos metodológicos.

Um dia normal do pesquisador conterá: lecionar algumas aulas, orientar alguns alunos de mestrado e doutorado, além de escrever as suas pesquisas. Em um dia produtivo e realmente bom, poderá ter avançado uma página inteira. Porém, no dia seguinte, quando relê o que escreve, possivelmente irá reescrever e reorganizar uma grande parte 
do texto anterior. É assim que o artigo evolui: com pequenos progressos diários. Nas ciências sociais, de modo geral, a qualidade da redação talvez seja ainda mais importante do que nas ciências mais duras, mas se desengana quem pensa que o pesquisador apenas verte para o papel uma pesquisa que está bem fundamentada e solidificada na mente. Não! Na realidade, há uma enorme evolução do artigo e das ideias durante o processo de redação. Um progresso que se vai permitindo às interações do autor pesquisador com seus textos, leituras e pensamentos.

Com este ensaio, pretendo atingir alguns resultados. $O$ primeiro é partilhar, ou relembrar, alguns insights, talvez não tão novos, mas que valem a pena recordar ou, no caso de estudantes de Mestrado e Doutorado, aprender e usar em suas pesquisas. Segundo, reforçar a importância de planejar cuidadosamente a pesquisa desde o início. Um bom planejamento inicial ajudará muito a conseguir apresentar o trabalho mais tarde, publicado em um periódico. Terceiro, expressar a opinião que uma escrita clara é tão importante como uma pesquisa que segue todos os preceitos metodológicos e científicos. Não se comunica ciência e novos conhecimentos em textos confusos, desorganizados, sem um foco evidente. Este aspecto de uma escrita bem clara ainda é muito descurado, inclusive, na formação doutoral. Os estudantes aprendem as teorias e os conceitos, conseguem dominar os métodos, mas têm grandes lacunas na sua comunicação escrita (GRANT; POLLOCK, 2011). Assim, o resultado e contribuição deste artigo é especialmente dirigido aos jovens estudantes e pesquisadores, contribuindo para melhorar as suas pesquisas e, especialmente, a qualidade dos seus manuscritos de modo que consigam publicar em periódicos com impacto.

Com estes fins em consideração, organizo o presente ensaio em três partes. Primeiramente, a partir do processo científico, descrevo de maneira sucinta a estrutura de um artigo científico. No segundo ponto, exponho um breve roteiro de atividades e cuidados a seguir enquanto se planeja e escreve o artigo. Por fim, na terceira parte, abordo o foco na redação ou escrita como elemento essencial para construção da história do artigo. 


\section{0 processo científico e a estrutura do artigo}

O processo científico é bem claro para os pesquisadores mais experientes, mas muito opaco para estudantes de doutorado e jovens doutores pesquisadores. Em essência, o processo científico pode ser representado como na Figura 1, a seguir. O processo começa com um problema ou questão, isto é, precisa visar um objetivo a ser alcançado, frequentemente divide a questão principal em subquestões mais "gerenciáveis" (que são as hipóteses), segue um plano de procedimentos metodológicos que envolvem a concepção de um instrumento, a coleta de dados, análise e interpretação dos dados para responder à questão de pesquisa inicialmente formulada.

Figura 1. O processo científico e o artigo

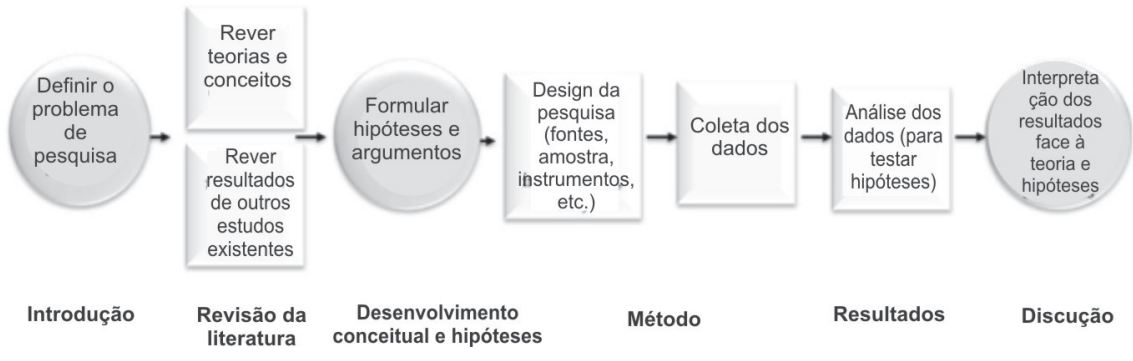

Fonte: o autor

Cada uma das "fases" do processo científico alimenta uma das partes do artigo: introdução, revisão da literatura, hipóteses, método, resultados, discussão e conclusão. Em seguida, exponho brevemente em que consiste cada uma destas partes do artigo. No entanto, um artigo começa com título, resumo e palavras-chave, que analisamos primeiro.

Título. A primeira página contém o título do artigo, nomes dos autores, respetivas filiações e dados de contato. Confirme se os dados estão corretos. Um e-mail errado pode atrasar todo o processo e fazer com que as cartas de resposta se percam no ciberespaço.

A importância do título vai além de mera atratividade. Um título precisa ser informativo do conteúdo do artigo e é o primeiro sinal de 
tema e história do artigo. O título tem um impacto fundamental na fase de avaliação por revisores, na medida em que, ao ler o título, o revisor formula um conjunto de expectativas quanto ao conteúdo do artigo que precisam ser satisfeitas. Títulos demasiado abrangentes não veiculam bem o conteúdo. Por exemplo, "A internacionalização das empresas brasileiras" pode ser título para livro, mas não para artigo em periódico. É por meio do título que há uma primeira oportunidade para captar a atenção de um potencial leitor. De igual modo, um título que seja interessante possivelmente será mais facilmente memorizado e, eventualmente, citado no futuro. Portanto, se o autor pretende ter um título atrativo, pode fazê-lo, desde que também seja informativo do real conteúdo do artigo.

Resumo e palavras-chave. O resumo é uma das seções que surgem primeiro no artigo, logo após o título, que os potenciais leitores "escaneiam" para decidir se vale a pena ler mais. Possivelmente, a maioria dos artigos não chega a ser lida para além do resumo, porque o autor não consegue atrair o leitor. Assim, é comum observar artigos que dizem mais ou menos o seguinte: "face à crescente globalização, o tópico x se torna mais relevante. Usamos a teoria x e y e z para avançar com um modelo e propor uma agenda de pesquisa brasileira. Este estudo exploratório usou de dados coletados... O trabalho conclui com uma discussão e apontando pistas para pesquisas futuras". Embora o autor tenha cerca de meia página para escrever o resumo, é conveniente conseguir atrair o leitor. Pelo menos em parte, isso pode passar ao se começar com uma indicação de qual é a história no resumo (regressaremos à importância da história mais à frente).

Então, o que deve constar no resumo? Em essência, são cinco os elementos fundamentais: (1) indicação da relevância ou pertinência do tema; (2) questão de pesquisa; (3) método usado e contexto empírico, (4) principais resultados; e (5) contribuição ou implicação. No entanto, embora seja relevante indicar qual a corrente teórica que usa no artigo, não é boa ideia usar referências em um resumo, exceto em situações nas quais se vai utilizar especificamente um trabalho como base para o seu. Esta situação é frequente em críticas de trabalhos anteriores 
ou para aplicações, principalmente, empíricas de modelos e conceitos existentes, mas deve-se evitar incluir referências em todas as outras situações.

As palavras-chave são relevantes na medida em que são um dos campos usados pelos motores de busca quando fazemos pesquisa em qualquer base de dados, como a ABI-Inform, ProQuest, Ebscoetc e mesmo no Google Scholar. Idealmente, as palavras-chave devem refletir o conteúdo do artigo no seu todo. Usualmente, um artigo conterá entre três e seis palavras-chave. Enquanto umas se referirão a questões de procedimentos ou de amostra, outras podem ser relativas à teoria ou ao contexto.

Introdução. Antes de começar a escrever a introdução, pense qual é a sua contribuição. O que os leitores devem recordar do artigo? Uma introdução pode variar entre três a seis parágrafos para a maioria dos artigos - embora muitos tenham uma introdução bem mais longa que o necessário e até desejável - pelo que não é a seção para grandes e profundas explicações sobre os desafios da globalização, a emergência do Brasil na economia mundial ou as carências de pesquisa nacional face à internacionalmente publicada. É necessário focar no que será retido pelos leitores, ainda que proporcione um conjunto de outras informações sobre o artigo.

Como seu trabalho se posiciona na literatura? A introdução deve ser bem clara ao estabelecer quais as fundações conceituais do estudo. Isto não significa uma extensa revisão da literatura, mas que precisará referir alguns trabalhos fundamentais de modo a evidenciar mais qual a linha onde se posiciona e o debate que estabelece com a pesquisa já existente.

Há dois aspectos que são importantíssimos na introdução. Primeiro, propiciar alguma informação sobre a relevância ou importância do tema revelando, como já examinado em estudos anteriores e, a partir disso, justificar a necessidade de fazer este estudo. O estudo terá, assim, contribuição e implicações. Segundo, indicar qual a questão de pesquisa e como, metodologicamente, o autor busca a resposta à questão. 
Revisão da literatura. A revisão da literatura tem uma função primordial: o autor mostrar que conhece a literatura relevante em que posiciona seu artigo. A literatura relevante incluirá alguns trabalhos seminais e, também, trabalhos mais recentes, de modo a cobrir os desenvolvimentos atuais sobre o tema. Aqui, o autor mostra sua maestria e que entende os conceitos fundamentais. Importa, assim, construir uma revisão de literatura bem focada; o objetivo não é incluir todas as teorias e todos os conceitos possíveis. Face às limitações de espaço nos periódicos, esta seção tem vindo a tornar-se mais curta e, em alguns casos, acaba por ser fundida com a seção seguinte de hipóteses.

Uma das falhas mais comuns ao escrever a revisão de literatura, comum entre estudantes, é organizar por obra. Assim, muitos parágrafos começam com "Segundo xxx (ano)..." ou "xxx (ano) argumentou que...". Mas a revisão de literatura deve ser centrada em conceitos e teorias, não em obras específicas. As referências à literatura são, portanto, usadas para dar evidência e detalhes adicionais sobre os estudos.

Outra das falhas comuns é tornar a revisão de literatura uma revisão estatística ou de contexto. Revisão estatística, porque os autores focam nos resultados empíricos da literatura anterior. Revisão do contexto, porque incluem seções do contexto, por exemplo, os dados econômicos das economias emergentes dos BRIC (Brasil, Rússia, Índia e China). Não é demais recordar que a revisão da literatura precisa assentar sobre a teoria e os conceitos.

Hipóteses. A seção de desenvolvimento conceitual e hipóteses é onde o autor expõe o seu modelo. Com modelo não significamos que necessitará obrigatoriamente de uma figura, embora possa ser útil representar as hipóteses graficamente. Em essência, as hipóteses irão refletir o que de novo o autor propõe no seu artigo e muitos leitores vão diretamente às hipóteses para entender rapidamente em que consiste o artigo mais especificamente.

Para construir uma boa seção de hipóteses é relevante procurar entender o que é e como se constrói teoria. O trabalho de David Whetten (1989) - "What constitutes a thoeretical contribution?" - pode auxiliar, mas 
há um conjunto adicional de outras leituras que podemos recomendar, como Sutton e Staw (1995), sobre método e dados não serem teoria e como construir teoria, de Mitchell e James (2001); sobre a construção de melhor teoria e a crítica de Weick (1999) ao pouco desenvolvimento teórico em muitos dos artigos publicados quando os pesquisadores assumem posturas conservadoras, focadas mais na publicação do que no conhecimento.

Uma hipótese é uma proposta de relação entre duas ou mais variáveis. Ao construir a hipótese, é relevante recordar que a hipótese não é uma afirmativa: é uma proposta que será testada e necessita ter pelo menos duas variáveis, estabelecendo qual a direção e qual o sentido da relação entre as variáveis. No fundo, isto significa que a hipótese precisa indicar qual é a variável independente e dependente, se a relação entre as variáveis é positiva, negativa ou curvilinear (em alguns casos pode propor uma relação baseada em uma função mais complexa, por exemplo, polinomial). Não se expõe a hipótese nula, que não há relação entre variáveis, até porque não teria muito sentido estudar algo propondo que não há relação.

A prática comum é colocar as hipóteses após o texto que desenvolve o argumento. Assim, cada hipótese decorrerá naturalmente dos argumentos que a antecedem e nunca deve surgir como uma surpresa ou na forma de uma listagem de hipóteses sem a respetiva fundamentação. O que isto significa é que há três cuidados fundamentais a ter nesta seção (ver SPARROWE; MAYER, 2011): (i) deixar claro o posicionamento das hipóteses na pesquisa existente, (ii) criar um argumento lógico que explica as principais variáveis e por que se propõem estas hipóteses, ou seja, estas relações entre as variáveis, e (iii) garantir que o conjunto das hipóteses seja coerente. Criar o posicionamento exige um equilíbrio entre as referências aos trabalhos existentes e os argumentos próprios que desenvolve. O objetivo desta seção não é rever literatura, mas sim construir um argumento lógico. Portanto, começar os parágrafos com frases como: "Segundo Fiates (2009), as organizações..." não é a forma adequada, mas será adequado usar a referência para sustentar, mesmo que em parte, algum argumento (ver SUTTON; STAW, 1995). 
Método. A seção de método é relativamente simples se tiver o cuidado de enunciar os procedimentos de coleta de dados, descrever a amostra, instrumentos, variáveis e procedimentos de análise dos dados. Ainda assim, muitos artigos acabam por ser rejeitados por falhas nesta seção ou pelos métodos usados para responder à questão de pesquisa não serem adequados ou estarem incompletos. Possivelmente, falhas metodológicas serão difíceis de corrigir em fase avançada do artigo.

O que deve incluir nesta seção é uma descrição do método usado, mas com o detalhe suficiente para o leitor conseguir entender e, se desejar, replicar. Isto significa indicar com precisão quais as variáveis e como são mensuradas, descrever o instrumento (por exemplo, um questionário), apontar as fontes dos dados secundários ou como os dados primários foram coletados e com que participantes. Frequentemente descurada é a descrição precisa e clara das variáveis (dependente, independentes, moderadoras ou mediadoras e de controle). Cada explicação de cada variável necessita ser completa, incluindo o que ela significa, como é medida (unidade de medida, escala etc.), qual a fonte dos dados usados na mensuração e, sempre que possível, indicar outros artigos que tenham usado a mesma, ou similar, variável.

Seguindo os três C de Zhang e Shaw (2012), a seção de método precisa ser Completa, Clara e Credível, acrescento um quarto $\mathbf{C}$ de Coerente com as análises feitas e resultados reportados. Por exemplo, não é coerente enunciar dados de entrevistas ou de questionários como elementos fundamentais e não os reportar. Também, não é credível dizer que coletou outros dados que suportam as análises, mas que não são mostrados em um artigo, porque irá publicar em outro. O leitor não duvida, mas não pode confirmar. A claridade está em explicar exatamente o que se fez. Por exemplo, enunciar que "adaptamos o questionário..." não é suficiente. Como foi adaptado? Por que foi adaptado em vez de usar o questionário original? Mas a credibilidade também inclui explicar a amostra. Por que a amostra é adequada? Por que os casos de estudo foram estes e não outros? Como são ajustados a responder à questão de pesquisa? Mesmo as variáveis e a sua operacionalização necessitam ser adequadamente explicadas. Uma lacuna usual parece estar na 
insuficiente explicação de variáveis de controle (ZHANG; SHAW, 2012), porque não basta dizer que foram incluídas. Por que estas e não outras? Como estas variáveis de controle podem cobrir explicações alternativas ao modelo conceitual proposto?

Note que os requisitos se mantêm independentemente do tipo de estudo. Por exemplo, em um estudo qualitativo com entrevistas, importa entender quais foram os participantes e como esses são indicados. Se há um roteiro de entrevista, que questões foram colocadas. Como os dados foram analisados. Se for um estudo de caso, importa, especialmente, entender suas características, como esse caso foi selecionado e como é ajustado face à questão de pesquisa.

Uma forma de organizar esta seção é criar subtítulos para compartimentalizar as descrições. Neste caso, podemos considerar uma subseção para: (a) procedimentos de coleta dos dados; (b) amostra; (c) variáveis; (d) técnicas de análise dos dados; e outras que sejam necessárias face às especificidades do estudo.

Resultados. A seção de resultados tende a ser uma das seções mais simples de fazer se tudo o resto estiver bem concebido e executado. O principal na seção de resultados é mostrar efetivamente quais foram os resultados dos seus testes estatísticos que emergem dos dados coletados. Assim, a palavra de ordem é ser bem objetivo e explícito no texto, sem enveredar por análises paralelas ou fora do foco requerido pela questão de pesquisa e hipóteses.

Em estudos empíricos, é usual começar por apresentar uma tabela de correlações com também algumas estatísticas descritivas como média, máximo, mínimo e desvio padrão. As correlações não são os testes estatísticos, mas ajudam a construir credibilidade e apresentam os dados aos revisores e leitores. Por exemplo, correlações altas podem sinalizar multicolinearidade (reporte o VIF - Variance Inflation Fator). A apresentação dos restantes resultados deve ser bem precisa. Usualmente, incluindo tabelas de regressão (mas não diretamente o output do SPSS, é necessário formatar as tabelas de acordo com as normas usuais) onde ficam claras o tamanho da amostra, as variáveis, 
os coeficientes e as significâncias. Entretanto, é preciso escrever no texto se as hipóteses se confirmam ou não. Esta indicação está incluída na seção de resultados e não na discussão. A sugestão é seguir, no mínimo, o formato clássico de apresentação dos testes das hipóteses com um texto como o seguinte: "A hipótese x propôs que... Os resultados no modelo... na tabela... mostram que... Assim, a hipótese x não é suportada". Todas as hipóteses, sejam ou não confirmadas, devem ser enunciadas nesta seção.

Crescentemente, os revisores solicitam a inclusão de testes estatísticos de sensibilidade, também designados testes de robustez. Considere esta necessidade logo na fase de planejamento, de modo que, quando entrar na fase de coleta de dados, já seja incorporada a necessidade de ter análises adicionais de robustez.

Discussão. Esta seção é fundamental para avaliação por pareceristas. Na realidade, embora seja uma seção fulcral e muitos não saibam como a começar, o início é simples. Comece com "Neste estudo, procuramos...", recordando a questão de pesquisa, podendo continuar com "O estudo contribui para...", relembrando qual contribuição, implicação e novidade do trabalho. Em seguida, pretende-se sumariar os resultados principais por frases simples, como "Os resultados mostram que...". Esta pode ser uma forma de abrir.

A discussão não deve ser usada para apresentar novos dados ou testes estatísticos, para sumariar um conjunto de hipóteses, para introduzir novas teorias, nem para reproduzir novamente o texto da introdução. Também, não é objetivo da discussão analisar extensamente os resultados. O fundamental é fazer a integração entre teoria-hipótesesresultados.

Em certos casos, os resultados apenas confirmam o que outros estudos já analisaram e, nessa situação, encontrar a sua contribuição será substancialmente mais complexo e o artigo mais difícil de ser aceito para publicação. Por quê? Possivelmente, por ausência de novidade. Em outros casos, é possível que os resultados contrastem com a pesquisa anterior, mas será preciso explicar o porquê. Efetivamente, parte da 
concepção do estudo também assenta em planejar para os resultados não serem os esperados ou para que contradigam pesquisas anteriores. Este planejamento visa responder à questão "por quê". Em todo caso, na discussão, deve-se sempre evitar afirmativas vagas e não sustentadas nos dados ou resultados, assim como especulações para as quais não há quaisquer evidências.

A discussão deve incluir as limitações do trabalho e sugestões para pesquisas futuras. Aqui, a situação ideal é organizar um parágrafo para cada limitação-pesquisa futura-contribuição. Ou seja, uma limitação dará origem a uma pesquisa futura, a que segue uma explicação de como seria importante fazer essa pesquisa para desenvolver o conhecimento ou resolver um paradoxo ou inconsistência. Recorde que apenas porque algo não foi ainda estudado não significa que seja pertinente fazê-lo. De modo similar, o leitor também não está interessado em ler todas as limitações empíricas do seu estudo. Uma listagem de todas as limitações empíricas é contraproducente. Escreva o que é realmente relevante, indicando por que é relevante.

Referências. Durante a redação do artigo, faz-se boa prática apontar todas as referências utilizadas, pois, mais tarde, pode ser que não recorde. Quanto à formatação das referências, não há segredos: antes de submeter ao periódico, siga as instruções de formatação disponibilizadas aos autores.

A seguir, apresentamos no Quadro 1 uma seleção de trabalhos que orientam a elaboração de um artigo científico.

Quadro 1. Uma seleção de trabalhos sobre a estrutura e conteúdo do artigo

Booth, Colombe Williams (2003). The craft of research, Chicago: University of Chicago Press.
Um livro bem completo que explica cada uma das partes de um artigo, como construir um argumento, como escrever introduções, discussões e conclusões e como planejar uma pesquisa 
Bartunek J., Rynes, S. Ireland, R. (2006). What makes management research interesting, and why does it matter? Academy of Management Journal, 49, 9-15.

Bono, J. e McNamara, G. (2011). Publishing in $A M J-$ Part 2: Research design. Academy of Management Journal, 54(4), 657-660.

Sparrow R. e Mayer, K. (2011).

Publishing in $A M J$ - Part Comentário editorial que foca a construção das 4: Grounding hypotheses. hipóteses e a importância da argumentação Academy of Management prévia à hipótese Journal, 54(6), 1098-1102.

Zhang, Y. e Shaw, J. (2012). Publishing in AMJ - Part 5: Crafting the methods and results. Academy of Management Journal, 55(1) 8-12.

Swales, J. e Najjar, H. (1987). The writing of research articles introductions. Written Communication, 4(2), 175-191.

Khun, T. (2003) A estrutura das revoluções científicas. 7.ed, São Paulo: Perspectiva.
Ser interessante não é o fundamental do trabalho científico e não se sobrepõe à pertinência da questão de pesquisa e validade dos resultados. Neste artigo, enunciam algumas características de pesquisas interessantes.

Proporciona uma listagem de aspectos de concepção, ou design, nos estudos que frequentemente levam à rejeição dos artigos. Não foca a metodologia em si, mas antes aspectos que podem ser inadequadamente planejados e concebidos a priori, mas que podem ser, na generalidade, evitados.

Comentário editorial focado em duas seções do artigo: método e resultados. Contém ótimas dicas a seguir e aponta algumas das lacunas que podem surgir e cuidados a ter.

Muitos autores clamam que a introdução é uma das partes mais difíceis de escrever e que, seguida ao título e ao resumo, é a parte mais lida. Mas como escrever a introdução? Este artigo dá umas indicações relevantes a seguir e alternativas de como organizar melhor para contar uma história. Sugiro a leitura adicional de Colquitt e George (2012) sobre a escolha do tópico.

Embora possa parecer estranho recomendar Khun para estudantes de doutorado, é relevante entender que o progresso científico, ou no conhecimento, segue uma racionalidade de incrementalismo. Assim, o estudante quer construir sobre um conhecimento já existente e não criar algo completamente novo. Previsivelmente, ajudará inclusive a entender a lógica a seguir nas referências a trabalhos anteriores. 


\begin{tabular}{|c|c|}
\hline $\begin{array}{l}\text { Whetten, D. (1989). What } \\
\text { constitutes a theoretical } \\
\text { contribution? Academy of } \\
\text { Management Review, 14, 490- } \\
495 .\end{array}$ & $\begin{array}{l}\text { Artigo influente que suscitou um debate na } \\
\text { academia sobre o que é teoria e a importância } \\
\text { de o autor se posicionar na conversação, } \\
\text { contribuindo para a teoria nos estudos. } \\
\text { Atualmente, os autores precisam deixar bem } \\
\text { clara qual será a contribuição logo na introdução } \\
\text { (ou mesmo no resumo) do seu artigo. }\end{array}$ \\
\hline $\begin{array}{l}\text { Barley, S. (2006). When I write } \\
\text { my masterpiece: Thoughts on } \\
\text { what makes a paper interesting. } \\
\text { Academy of Management } \\
\text { Journal, } 49(1), 16-20 .\end{array}$ & $\begin{array}{l}\text { Trabalho efetivamente válido na forma como } \\
\text { trata a questão do que é interessante em um } \\
\text { artigo. Para Barley, o interesse advém da } \\
\text { diferença face à corrente na disciplina - seja } \\
\text { diferença na abordagem teórica, nos métodos, } \\
\text { no assunto - mas reconhece a necessidade de } \\
\text { conformidade ao padrão que vigora na estrutura } \\
\text { e organização. Especialmente relevante para um } \\
\text { momento inicial de planejamento da pesquisa } \\
\text { em que ainda pode pensar como construir uma } \\
\text { pesquisa interessante. }\end{array}$ \\
\hline $\begin{array}{l}\text { Serra, F., Fiates, G. e Ferreira, } \\
\text { M. (2008) Publicar é difícil ou } \\
\text { faltam competências? O } \\
\text { desafio de pesquisar e publicar } \\
\text { em revistas científicas na } \\
\text { visão de editores e revisores } \\
\text { internacionais. Revista de } \\
\text { Administração McKenzie, 9(4), } \\
\text { 32-55. }\end{array}$ & $\begin{array}{l}\text { Trata diversas dificuldades na publicação } \\
\text { dos artigos, a interação com os revisores e a } \\
\text { importância de selecionar o periódico. Inclui } \\
\text { algumas recomendações de editores e revisores } \\
\text { de periódicos internacionais para desenvolver } \\
\text { artigos que sejam publicáveis e a importância de } \\
\text { ter um pipeline de pesquisa em vez de apenas } \\
\text { um artigo em curso de cada vez. }\end{array}$ \\
\hline $\begin{array}{l}\text { Volpato, G. (2003). Desafios } \\
\text { na publicação científica. } \\
\text { Pesquisa Odontol Brasileira,17 } \\
\text { (Supl1):49-56. }\end{array}$ & $\begin{array}{l}\text { Inclui uma apresentação sobre o texto ser um } \\
\text { argumento lógico e descreve as principais partes } \\
\text { de um artigo acadêmico, questões de forma e } \\
\text { cuidados na redação. }\end{array}$ \\
\hline
\end{tabular}

\section{Uma proposta de roteiro}

Apresento, agora, um breve roteiro para a redação de artigos científicos. Este roteiro não tem por objetivo ser inclusivo de tudo, todas as falhas, lacunas e processos, mas apenas ajudar a evitar alguns dos "problemas" comumente observados quando os pesquisadores 
escrevem seus artigos. Estendo a sugestão de completar o roteiro com alguns aspectos já identificados nos seus trabalhos. Enquanto escreve e reescreve, vá verificando o roteiro.

Ainda antes de começar a escrever, por que não ler um pouco sobre o próprio processo de escrever? Há um extenso conjunto de leituras que podem ajudar a comunicar mais efetivamente. Por exemplo, Flaherty (2009) em "The elements of story" pode ser útil para entender a perspectiva de um jornalista na comunicação de uma história. Huff (1999), em "Writing for scholarly publication", é especificamente direcionado para a redação de artigos científicos em ciências sociais, com dicas relevantes de redação. Strunk e White (2000), em "The elements of style", focam exatamente o estilo na redação e, embora seja específico para textos em inglês, contém pistas que serão úteis a todos os pesquisadores. "On writing well", de Zinsser (2006), é um roteiro para escrever. Leituras adicionais incluem os trabalhos de Hale (1999), King (1999), Silva (2007), entre outros. Especificamente com orientações para escrever artigos acadêmicos em Administração, recomendo a leitura dos comentários editoriais de Colquitt e George (2011), Bono e McNamara (2011), Grant e Pollock (2011), Sparrowe e Mayer (2011), Zhang e Shaw (2012) e Geletkanycz e Tepper (2012) no Academy of Management Journal.

\subsection{Início: Planeje o artigo}

Comece por colocar a estrutura básica do artigo em um arquivo MsWord. Ou seja, crie um arquivo, dê-lhe um nome, a primeira página será a capa com título, nomes, filiações e endereços dos autores. A segunda página terá título, resumo e palavras-chave (repetir para versão em inglês, se for necessário). A terceira página começa com a introdução e, sucessivamente, todas as partes do manuscrito. Quais são as partes? Escreva as seguintes: Introdução, Revisão da literatura, Hipóteses, Método, Resultados, Discussão, Conclusão e Referências.

Para quem vai escrever? Ou seja, qual a audiência? A audiência tem periódicos específicos? Se sim, estude os artigos publicados nesse 
periódico. E qual o estilo que pretende na escrita? Por exemplo, ao escrevermos este texto, temos um objetivo bem mais didático do que em seguir estritamente os preceitos científicos comumente observados.

Qual é a história ou a mensagem que quer comunicar? Curiosamente, embora o artigo típico em Administração tenha talvez umas 25 a 30 páginas, a sua mensagem central deve ser expressa em uma ou duas frases. Anote desde o início qual é essa mensagem e recorde, à medida que vai revendo o texto, qual é a mensagem e se está sempre presente, orientando o texto. Esta história, ou mensagem, provavelmente vai surgir escrita no resumo, na introdução e na discussão do artigo. É a partir desta que será possível conseguir escrever claramente qual a contribuição que pretende com o artigo.

Embora frequentemente sugiram que partilhe seu trabalho com colegas, muitos pesquisadores resistem a esta prática. Caso a sugestão vá mesmo mais longe e consista em partilhar versões iniciais com colegas, se tiver oportunidade, discuta as ideias ainda antes de começar a debruçar-se sobre a pesquisa. Assim, o autor conseguirá ter, imediatamente, um feedback e até talvez se beneficie de alguns insights sobre novas direções para a pesquisa e sobre outras teorias relevantes.

\subsection{Durante: Enquanto escreve}

Há muitos cuidados que o autor pode ter enquanto escreve e reescreve seu artigo. Alguns são apenas aspectos de formatação que, se forem corrigidos e ajustados, irão poupar um tempo precioso no final. Outros são aspectos que exigem organização e atenção, podendo poupar tempo e aborrecimentos futuros. Exponho alguns em seguida.

Uniformize os espaçamentos do texto ao longo de todo o artigo. Verifique o tipo e tamanho de letra e vá garantindo que a formatação do artigo segue a solicitada pelo periódico ao qual pretende submeter. Por exemplo, as referências bibliográficas seguem as normas indicadas? A formatação de títulos e subtítulos é a adequada? As tabelas e as figuras são suas ou as fontes estão corretamente indicadas? As tabelas e as 
figuras estão numeradas sequencialmente, têm um título e são referidas no corpo do texto? É clara qual a unidade de medida nas tabelas e figuras? Há excertos no texto e estão bem citados? Atenção ao plágio.

Outros aspectos são menos de forma e mais de conteúdo. Por exemplo, as tabelas e figuras são realmente necessárias ou são apenas repetitivas face ao texto? O seu texto é coerente face aos dados das tabelas e figuras?

O texto está escrito de forma coerente e sequencial? Se é certo que um bom texto se constrói nas múltiplas interações, sugerimos que os autores observem em especial o fluxo das ideias e a sua coerência ao longo do artigo. Uma das sugestões que damos é examinar o conteúdo de cada parágrafo. O conteúdo do parágrafo decorre logicamente da primeira frase? Note que a primeira frase do parágrafo, a frase-líder, deve sempre orientar o conteúdo de todo o parágrafo. Assim, podemos pensar o artigo como uma sequência de frases-líder.

\subsection{Durante: Reescrever, reescrever e reorganizar}

Como comecei a observar, tipicamente, o pesquisador usa mais tempo na revisão e reescrita do artigo do que na redação da primeira versão (JONSSON, 2006). Durante as revisões, o pesquisador vai estar atento a inúmeros aspectos, desde incorporação de novas referências até reformulação de frases e alteração de palavras. Durante estas interações do autor com seu texto, a mensagem final vai sendo moldada.

Contudo, no momento, sugiro que foque um aspecto em específico: a coerência do artigo quanto à forma como as ideias fluem desde a introdução à conclusão. Especificamente, organize o texto em torno de frases-chave. Estas frases, que designamos por frases-líder, iniciam o parágrafo, tendo o restante corpo do parágrafo a função de dar suporte. A frase-líder sinaliza o conteúdo do parágrafo e deve ser suficientemente específica para o leitor entender o foco do parágrafo. Assim, durante o processo de reescrever o texto, o autor precisa ir se perguntando como este texto se prende à frase-líder? Como a ideia é relacionada? Como 
dá suporte? Williams e Colomb (1990) referem que a frase-líder não necessita ser a primeira, mas quanto mais tarde surgir, mais longo tende a ser o parágrafo e mais difícil se torna para o leitor conseguir entender qual "ponto" o autor quer enfatizar. Em seguida, analise a sequência destas frases-líder de cada parágrafo. Copie apenas as frases-líder e veja se o fluxo que indicam é o que pretende. Se não for, ajuste.

Ainda, durante a reescrita, sugiro que analise a extensão do parágrafo. Não há uma extensão máxima para um parágrafo, mas frequentemente os leitores não apreciam ler parágrafos demasiado longos. O fundamental, ainda assim, é que a divisão do texto em parágrafos não seja feita por questões de estética. Como referido acima, um parágrafo deve veicular uma ideia, tendo seu corpo a função de sustentar e proporcionar evidência.

Importante é examinar o fluxo das ideias ao longo do texto. $\mathrm{Na}$ prática, isto significa que os leitores esperam que exista uma sequência no texto acadêmico. Há, obviamente, a sequência na estrutura do artigo que esperamos (começa com título, resumo, introdução, revisão da literatura até referências). Mas há, também, a sequência dentro de cada seção, construída pela sequência das frases-líder dos parágrafos. Assim, será muito mais simples entender toda a história do artigo: uma organização em seções (títulos e subtítulos) que indicam o conteúdo em termos gerais e, dentro destas seções, uma organização por parágrafos comandados por frases-líder que são suportadas por argumentação e evidência no corpo do parágrafo. É durante a reescrita que esta sequência e coerência ganham forma.

No processo de contar a história no artigo (FLAHERTY, 2009; POLLOCK; BONO, 2013), títulos e subtítulos são elementos efetivamente importantes. Como referimos anteriormente, para o título do manuscrito, também os subtítulos ao longo do manuscrito, inclusive os de cada seção e subseção, devem ser bem explícitos e ilustrativos do conteúdo. A abordagem clássica e mais segura é designar cada uma das seções pelo seu propósito. Por exemplo, designar por 'Revisão da literatura' a seção onde inclui o referencial teórico de suporte. Entretanto, os 
subtítulos dentro de cada uma das seções devem também ser pensados e organizados para simplificar a leitura e orientar o leitor. Subtítulos demasiado generalistas não são úteis, ao contrário, podem confundir. Por exemplo, ter um subtítulo designado por "Teoria dos Custos de Transação" é muito abrangente e diz pouco sobre o real conteúdo. Mas podemos delimitar melhor para "Teoria dos Custos de Transação em negócios internacionais" ou, ainda mais especificamente, "A Teoria dos Custos de Transação na formação de alianças estratégicas". A função dos títulos é guiar o leitor, inclusive, em fase inicial, auxiliar o autor para que não perca o foco do que é fundamental tratar face à questão de pesquisa.

Uma história só é bem contada através de um texto claro, direto e preciso. Infelizmente, temos o hábito de pensar que os estrangeiros que escrevem em inglês têm uma vantagem de língua e que é o português uma língua que não ajuda a escrever de forma clara e objetiva. Efetivamente, o problema não está na língua, mas no escritor. Tendemos a escrever frases longas e confusas, com o uso desnecessário de pretencioso jargão científico, em raciocínios circulares e repetitivos, com a adição de expressões que buscam ligar frases. Acrescentadas a estes males, temos dificuldades na pontuação e em assumir a autoria do trabalho. Mas as regras (ver STRUNK;; WHITE, 2000; ZINSSER, 2006) são claras: eliminar cada palavra que não seja realmente necessária, usar palavras mais curtas (por exemplo, em vez de "utilizar" ou "empregar", podemos escrever simplesmente "usar"), eliminar advérbios que já são expressos nos verbos, corrigir as frases em voz passiva e usar antes a voz ativa, entre outras.

Há um conjunto adicional de pequenos "detalhes" que se deve manter sempre em mente durante a reescrita, incluindo os seguintes:

- Verificar a ortografia. Evitar erros ortográficos é muito mais simples com as funções de revisão dos processadores de texto atuais, mas há palavras que não estão erradas, apenas não são as corretas no contexto da frase. Por exemplo, 'mas' e 'mais'. 
- Evitar o uso de sujeitos indefinidos que dificultem a leitura, podendo tornar confuso a quem o autor se refere.

- Evitar frases demasiado longas. É comum o autor perder o foco e o leitor não entender frases muito longas. Usualmente, é apenas uma questão de dividir em duas uma frase longa ou de eliminar aspectos e detalhes que, efetivamente, não são relevantes.

- Analisar como se usam os tempos verbais consistentemente. Não é incomum, em mesmo parágrafo, os autores usarem diferentes tempos verbais, tornando o texto confuso.

- Analisar a coerência no uso do singular e do plural (exemplo: “As empresas é....). Usualmente, não são por erros ortográficos que se necessita reler atentamente todo o manuscrito.

- Observar a pontuação. Uma pontuação incorreta altera completamente o significado das frases. Talvez o mais relevante é que tendemos a escrever frases muito longas em que, ou o autor domina muito bem as regras de pontuação, ou o texto ficará efetivamente de difícil compreensão, perdendo assim a noção de quem é o sujeito e qual a ação.

- Encurtar as frases sempre que possível para torná-las mais simples de ler e entender. Um texto bem escrito provavelmente será equilibrado e variado em frases mais curtas, diretas e objetivas e frases mais longas, em que explica conceitos e argumentos. Ao fazer o esforço de encurtar frases longas, é possível que identifique aspectos que não são relevantes ou, pelo contrário, requerem maior desenvolvimento.

- Reler e rever sempre os progressos anteriores em cada interação com o artigo.

A seguir, apresentamos no Quadro 2 um conjunto seleto de referências para apoiar a escrita de artigos científicos. 
Quadro 2. Uma seleção de referências para auxiliar a escrever com clareza e elegância

\begin{tabular}{|c|c|}
\hline $\begin{array}{l}\text { Ragins, B. (2012). Editor's } \\
\text { comments: Reflections on the } \\
\text { craft of clear writing. Academy } \\
\text { of Management Review, } 37(4) \text {, } \\
490-501 .\end{array}$ & $\begin{array}{l}\text { Questiona e sintetiza as opiniões de editores } \\
\text { e revisores da AMR sobre a qualidade da } \\
\text { redação dos artigos, apontando pistas sobre } \\
\text { o que não fazer. Alguns dos aspectos focados } \\
\text { incluem uma escrita opaca, assumir que o } \\
\text { leitor sabe o que o autor pensa (read my mind) } \\
\text { e a falta de uma história no artigo. }\end{array}$ \\
\hline $\begin{array}{l}\text { Flaherty, F. (2009). The elements } \\
\text { of story: Field notes on nonfiction } \\
\text { writing. New York: Harper Collins. }\end{array}$ & $\begin{array}{l}\text { Interessante leitura, repleta de pistas sobre } \\
\text { como fazer (como escrever) que coloca o } \\
\text { centro da atenção ao contar uma história, ao } \\
\text { invés de apenas executarnormas mecanizadas } \\
\text { de escrita eficiente. Este livro não foca os } \\
\text { aspectos de gramática nem de estilo, mas } \\
\text { sim como construir uma história que motive e } \\
\text { agarre o leitor. }\end{array}$ \\
\hline $\begin{array}{l}\text { Strunk, W., e White, E. (2000). } \\
\text { The elements of style (4th ed.). } \\
\text { Boston: Allyn \& Bacon. }\end{array}$ & $\begin{array}{l}\text { ve para quem escreve em inglês } \\
\text { sobre questões de escrita e os } \\
\text { omuns. Ainda assim, as pistas são } \\
\text { m qualquer língua. }\end{array}$ \\
\hline $\begin{array}{l}\text { Jonsson, S. (2006). On academic } \\
\text { writing. European Business } \\
\text { Review, 18(6), 479-490. }\end{array}$ & $\begin{array}{l}\text { Este artigo inclui um conjunto de } 13 \text { regras para } \\
\text { ser um pesquisador produtivo. Estas regras } \\
\text { incluem desde tornar a escrita de artigos um } \\
\text { hábito, até a revisão como o aspecto central da } \\
\text { redação e a publicação. }\end{array}$ \\
\hline $\begin{array}{l}\text { Chow, C. e Harrison, P. (2002). } \\
\text { Identifying meaningful and } \\
\text { significant topics for research } \\
\text { and publication: A sharing of } \\
\text { experiences and insights by } \\
\text { 'influential' accounting authors. } \\
\text { Journal of Accounting Education, } \\
20,183-203 \text {. }\end{array}$ & $\begin{array}{l}\text { autores analisam uma questão com que os } \\
\text { dantes de doutorado se debatem: como } \\
\text { lher um tópico de pesquisa que seja } \\
\text { ificativo. }\end{array}$ \\
\hline
\end{tabular}




\begin{tabular}{|c|c|}
\hline $\begin{array}{l}\text { Brutus, S., Aguinis, H. e } \\
\text { Wassmer, U. (2013). Self- } \\
\text { reported limitations and future } \\
\text { directions in scholarly reports: } \\
\text { Analysis and recommendations. } \\
\text { Journal of Management, } 39(1) \text {, } \\
48-75 \text {. }\end{array}$ & $\begin{array}{l}\text { Uma análise de conteúdo das limitações e } \\
\text { sugestões para pesquisas futuras que foram } \\
\text { incluídas em artigos publicados entre } 1982 \text { e } \\
2007 \text {, em periódicos de Administração. Estas } \\
\text { duas componentes são relevantes, talvez mais } \\
\text { especialmente na avaliação pelos revisores } \\
\text { pelo que importa entender como escrever } \\
\text { e organizar melhor. Mas é também útil para } \\
\text { estudantes de doutorado face à recomendação } \\
\text { que analisem as sugestões de pesquisa } \\
\text { futura para identificarem possíveis tópicos de } \\
\text { pesquisa. }\end{array}$ \\
\hline $\begin{array}{l}\text { Armstrong, J. }(1980) \text {. } \\
\text { Unintelligible management } \\
\text { research and academic prestige. } \\
\text { Interfaces, 10(2), 80-86. }\end{array}$ & $\begin{array}{l}\text { Com algum humor, revela como uma escrita } \\
\text { "acadêmica" significa opacidade e dificuldade } \\
\text { de entender. Este artigo é uma leitura breve } \\
\text { que nos permite observar o contraste para a } \\
\text { lógica dominante de escrita clara, na voz ativa, } \\
\text { dinâmica. }\end{array}$ \\
\hline
\end{tabular}

\subsection{Final: submeter a um periódico}

Por fim, o artigo está completo e revisado. A ortografia e gramática foram verificadas. As referências estão completas. O artigo já não tem marcações do autor e esperamos que este tenha oportunamente recebido feedback dos seus pares em eventos formais, como conferências, ou mesmo informais. Seguiram-se as etapas anteriores, o seu artigo foi planejado e redigido já direcionado a um periódico específico. A última etapa é submeter ao periódico escolhido. Antes de submeter o artigo ao periódico, analise se segue efetivamente todas as normas expressas aos autores. Estas são, essencialmente, normas de formatação.

Como a rejeição do manuscrito ou a oportunidade de rever são os resultados mais prováveis (não ter o artigo imediatamente aceito), incluo no Quadro 3 algumas leituras sobre o processo de revisão pelos pares e como lidar com revisores do artigo. 
Quadro 3. Uma seleção de referências sobre submissão e o processo editorial

\begin{tabular}{|c|c|}
\hline $\begin{array}{l}\text { Shugan, S. (2007). The editor's } \\
\text { secrets. Marketing Science, } \\
\text { 26(5), 589-595. }\end{array}$ & $\begin{array}{l}\text { Descreve as etapas porque passa um artigo } \\
\text { submetido a um periódico internacional. } \\
\text { Explica o papel de cada um doa agentes } \\
\text { envolvidos - autor, editor e revisores - e, } \\
\text { depois, em maior detalhe descreve as etapas } \\
\text { do processo editorial. }\end{array}$ \\
\hline $\begin{array}{l}\text { Samkin, G. (2011). Academic } \\
\text { publishing: A Faustian bargain? } \\
\text { Australasian Accounting Business } \\
\text { and Finance Journal, 5(1), 19-34. }\end{array}$ & $\begin{array}{l}\text { Apresenta uma revisão de literatura sobre o } \\
\text { processo de revisão pelos pares e usando a } \\
\text { sua própria história de uma revisão mostra } \\
\text { como os autores têm de navegar pelo } \\
\text { processo. }\end{array}$ \\
\hline $\begin{array}{l}\text { Hemmings, B., Rushbrook, P. } \\
\text { e Smith, E. (2007). Academics' } \\
\text { views on publishing refereed } \\
\text { works: A content analysis. Higher } \\
\text { Education, } 54,307-332 \text {. }\end{array}$ & $\begin{array}{l}\text { Apresenta os resultados de survey sobre as } \\
\text { perspectivas de acadêmicos sobre publicar, } \\
\text { ou não, em periódicos científicos e o valor } \\
\text { da publicação, o que motiva a publicar e } \\
\text { eventuais apoios que poderiam promover } \\
\text { maior produção científica. }\end{array}$ \\
\hline $\begin{array}{l}\text { Frey, (2003). Publishing as } \\
\text { prostitution? Choosing between } \\
\text { one's own ideas and academic } \\
\text { success. Public Choice, 116,205- } \\
223 .\end{array}$ & $\begin{array}{l}\text { Uma análise crítica a } \\
\text { pelos pares que está } \\
\text { revisores têm virtual } p \\
\text { artigos Ihes submetido }\end{array}$ \\
\hline & $\begin{array}{l}\text { A editora Elsevier disponibiliza um instrumento } \\
\text { para auxiliar os autores a escolher o periódico } \\
\text { mais adequado ao seu artigo. }\end{array}$ \\
\hline $\begin{array}{l}\text { Singh, J. (2003). A reviewer's } \\
\text { gold. Journal of the Academy of } \\
\text { Marketing Science, 31(3), 331- } \\
336 .\end{array}$ & $\begin{array}{l}\text { Reflexões pessoais como autor e, } \\
\text { especialmente, como revisor. Embora foque } \\
\text { majoritariamente a interação entre autores } \\
\text { e revisores, ajuda a refletir como podemos } \\
\text { evitar erros e melhorar os artigos. Um texto } \\
\text { bem escrito é essencial, mas Singh argumenta } \\
\text { a necessidade de focar os fundamentos - o } \\
\text { puzzle, dados adequados, a contribuição/ } \\
\text { implicações. }\end{array}$ \\
\hline
\end{tabular}


Bedeian, A. (2003). The manuscript review process: The proper roles of authors, referees, and editors. Journal of Management Inquiry. 12(4), 331338.
Discute o impacto dos revisores sobre o artigo final publicado, notando, por exemplo, que os revisores impactam substancialmente $o$ artigo final, com matérias de sua preferência e que os autores fazem alterações que consideram incorretas. Leitura útil para entender este o debate sobre o papel dos revisores e editores como gate keepers.

\section{Será exagerado o foco na redação?}

Parece exagerado o foco recorrente na redação. Afinal, o objetivo principal do pesquisador é fazer a pesquisa. Escrever o artigo é apenas uma atividade acessória à pesquisa. Embora estas três frases anteriores reflitam o pensamento de alguns pesquisadores, o objetivo nunca é apenas publicar um artigo. A disseminação do conhecimento não termina na publicação. É necessário que alguém queira ler, leia, cite e utilize os conhecimentos. Assim, além de professor, burocrata, orientador, o pesquisador tem de assumir as vestes de escritor ainda que de não ficção. Em uma etapa prévia para se chegar ao leitor, é necessário ultrapassar o crivo de editor e revisores que exigem trabalhos bem escritos.

Escrever não é um dom inato, nem um gene herdado. Exige treino, esforço, disciplina e perseverança para se tornar um bom comunicador da sua pesquisa. No fundo, como fomos expondo ao longo deste artigo, o objetivo é simplesmente o de comunicar efetivamente uma mensagem de forma clara. $\mathrm{O}$ bom comunicador consegue comunicar ciência de forma que motiva a leitura, prende o leitor e, eventualmente, muda a forma como ele vê e entende um fenômeno.

Penso que todos os pesquisadores procuram encontrar o segredo para esta "arte" da escrita, mas há poucos segredos a descobrir por que um texto bem escrito se molda gradualmente às revisões e reescritas. Talvez, uma das grandes dificuldades para o pesquisador comum seja entender o que significa escrever para um leitor; mas, como revisores, deparamo-nos com muitas afirmações que só podem ser claras para 
quem as escreveu, certamente não para quem as lê e não está na mente do autor. Uma escrita obscura e pouco precisa, em texto menos coerente, onde não se vislumbra qual o objetivo que presidiu ao estudo são os sinais comuns de textos pobremente escritos.

O segredo da "arte" de um texto bem redigido está no esforço depreendido ao escrevê-lo e no tempo usado na reescrita e revisão. Ainda assim, é notável a pouca disposição que temos em empregar esforço e tempo necessários para levar o novo conhecimento gerado à publicação. Ragins (2012) sistematizou algumas das tarefas que exigem esforço. É esforço que emerge na reescrita e revisão do manuscrito para garantir que cada palavra signifique o pretendido, que cada palavra é necessária e tem função bem definida, que não há palavras sem qualquer significado, que cada frase tem um propósito de contribuir para a história do artigo, que a redação é simples, precisa e direta. É neste processo de auto-escrutínio da ideia do manuscrito que a mensagem a comunicar ganha forma e fica mais clara. Zinsser (2006), por exemplo, afirmou que "Rewriting is the essence of writing well" - reescrever é a essência de escrever bem. E, portanto, a essência de escrever bem está no reescrever.

Escrever e publicar um artigo acadêmico não se trata apenas de mérito científico, é também um exercício de comunicação. Gunning (1952), no livro "The technique of clear writing", enunciou a importância de algumas regras para uma escrita clara e outros autores têm publicado trabalhos visando auxiliar os autores pesquisadores a comunicar melhor suas pesquisas. Por exemplo, Williams e Colomb (2010) expuseram algumas lições para escrever com clareza e graça no livro "Style: Toward clarity and grace". Booth, Colomb e Williams (2003) expuseram em "The craft of research" diversas pistas sobre questões de organização, conteúdo e redação de artigos científicos. Genericamente, muitos autores e editores de periódicos têm publicado textos que visam auxiliar os autores a publicarem suas pesquisas. Este foco na clareza, na fluidez, no texto, é interessante porque é evidência prima facie que não basta fazer ótima pesquisa, também é necessário saber comunicar essa pesquisa otimamente. 
Utilizando a ideia de escrever com clareza, o que isso realmente envolve? Em essência, significa escrever de forma que a leitura seja fácil de entender. Como fazer isto? Escrevendo com clareza, sendo preciso e direto na escrita e seguindo algumas dicas de como melhor comunicar. O que exige escrever com clareza? No fundo, é um trabalho moroso de rever e reescrever o texto, tendo atenção ao leitor, revendo e simplificando a forma como as ideias e os argumentos são expressos e sem assumir que o leitor é um especialista que entende perfeitamente qualquer coisa que escreva. Ou seja, há uma sugestão implícita: a de escrever sem pretenciosismos acadêmicos; o que não significa simplificar na ciência, mas sim tornar os conhecimentos apreensíveis por todos. $\mathrm{Na}$ experiência como revisor para periódicos, arrisco afirmar que muitos textos são confusos, porque são confusas as ideias na mente do autor.

\section{Notas Finais}

A ciência e a disseminação dos novos conhecimentos gerados exigem a publicação dos trabalhos em periódico. A publicação é o penúltimo ponto de legitimidade do trabalho e o último é a citação pelos pares. Mas, para publicar e ser citado, é preciso entender que não só ciência e procedimentos estão em causa. Uma excelente ideia, perfeitamente executada, mas pobremente redigida, possivelmente não será publicada. Para muitos pesquisadores, isto é chocante e reclamam que editores e revisores prestam demasiada atenção à redação e menos aos méritos efetivos do artigo.

A maioria dos pesquisadores aprendeu muito durante os estudos de Mestrado e Doutorado. Aprendeu sobre teorias, sobre conceitos, sobre métodos, sobre procedimentos de coleta de dados, sobre construção de questionários, sobre técnicas estatísticas e softwares específicos, porém poucos aprendem a escrever e comunicar. Ou seja, poucos aprendem, como referiu Feldman (2004), a converter um projeto de pesquisa em um artigo publicável. Efetivamente, a qualidade da comunicação é essencial para um artigo ultrapassar com sucesso o processo editorial e o escrutínio de editor e revisores. Comunicar com efetividade é contar 
uma história, seguindo a estrutura normal do processo científico, com uma redação clara, atrativa e eficiente.

\section{Referências}

BONO, J.; MCNAMARA, G. Publishing in AMJ Part 2: Research design. Academy of Management Journal, New York, v. 54, n. 4, p. 657-660, August 2011.

BOOTH, W.; COLOMB, G.; WILLIAMS, J. The craft of research. Chicago, IL: University of Chicago Press, 2003.

COLQUITT, J.; GEORGE, G. Publishing in AMJ - Part 1: Topic choice. Academy of Management Journal, New York, v. 54, n. 3, p. 432-435, June 2011.

FELDMAN, D. The devil is in the details: Converting good research into publishable articles. Journal of Management, New York, v. 30, n.1, p. 1-6, February 2004.

FLAHERTY, F. The elements of story. New York, NY: HarperCollins, 2009.

GELETKANYCZ, M.; TEPPER, B. Publishing in AMJ - Part 6: Discussing the implications. Academy of Management Journal, New York, v. 55, n. 2, p. 256-260, April , 2012.

GRANT, A.; POLLOCK, T. Publishing in AMJ - Part 3: Setting the hook. Academy of Management Journal, New York, v. 54, n. 5, p. 873-879, October , 2011.

GUNNING, R. The technique of clear writing. Madison: McGraw-Hill, 1952.

HALE, C. Sin and syntax: How to craft wickedly effective prose. New York-NY: Three Rivers, 1999.

HUFF, A. Writing for scholarly publication. Thousand Oaks: CA: Sage, 1999. 
LAMOTT, A. Bird by bird: Some instructions on writing and life. New York- NY: Anchor, 1994.

MITCHELL, T.; JAMES, L. Building better theory: Time and the specification of when things happen. Academy of Management Review, New York, v. 26, n. 4, p. 530-547, October , 2001.

POLLOCK, T.; BONO, J. Being Scheherazade: The importance of storytelling in academic writing. Academy of Management Journal, New York, v. 56, n. 3, p. 629-634, June , 2013.

RAGINS, B. Editor's comments: Reflections on the craft of clear writing, Academy of Management Review, New York, v. 37, n. 4, p. 490-501, October, 2012.

SILVA, P. How to write a lot. Washington DC: American Psychological Association, 2007.

SPARROWE, R.; MAYER, K. Publishing in AMJ - Part 4: Grounding hypotheses. Academy of Management Journal, New York, v. 54, n. 6, p. 1098-1102, December, 2011.

STRUNK, W.; WHITE, E. The elements of style. $4^{\text {th }}$ ed. Boston- MA: Allyn \& Bacon, 2000.

SUTTON, R.; STAW, B. What theory is not. Administrative Science Quarterly, Cornell, v. 40, n. 3, p. 371-384, September, 1995.

WEICK, K. Theory construction as disciplined reflexivity: Tradeoffs in the 90s. Academy of Management Review, New York, v. 24, n. 4, p. 797806, October, 1999.

WHETTEN, D. What constitutes a theoretical contribution?. Academy of Management Review, New York, v. 14, n. 4, p. 490-495, October 1989.

WILLIAMS, J.; COLOMB, G. Style: Toward clarity and grace. ChicagoMA: University of Chicago Press, 1990.

WILLIAMS, J.; COLOMB, G. Style: Lessons in clarity and grace, $10^{\text {th }}$ ed. New York- NY: Pearson Education, 2010. 
ZHANG, Y.; SHAW, J. Publishing in AMJ - Part 5: Crafting the methods and results. Academy of Management Journal, New York, v. 55, n. 1, p. 8-12, February 2012.

ZINSSER, W. On writing well: The classic guide to writing nonfiction. New York- NY: HarperCollins, 2006.

Artigo recebido em: 01/09/2014

Aprovado em: 22/12/2014 